\title{
Descrição de nova distrofia macular associada à síndrome dos cabelos anágenos frouxos
}

\author{
New macular dystrophyassociated with loose anagen hair syndrome
}

\author{
Mário Teruo Sato ${ }^{1}$ \\ Rodrigo Marzagão \\ Christine Graff ${ }^{3}$ \\ Jaime Arana ${ }^{4}$ \\ Ana Tereza Ramos Moreira ${ }^{5}$ \\ Nina Amália Brancia Pagnan ${ }^{6}$ \\ Enilze Maria de Souza Fonseca Ribeiro ${ }^{6}$ \\ Carlos Augusto Moreira Júnior ${ }^{7}$
}

\begin{tabular}{l} 
RESUMO \\
\hline Objetivos: Descrever os achados oftalmológicos, dermatológicos e de \\
microscopia óptica (MO) e microscopia eletrônica de varredura (MEV) de \\
nova distrofia macular associada à síndrome dos cabelos anágenos \\
frouxos (SCAF). Métodos: Uma família de sete pacientes, quatro deles \\
afetados, foi examinada. Os pacientes foram submetidos ao exame oftalmo- \\
lógico completo, teste de cores (Ishihara e Farnsworth D-15), ecografia, \\
angiografia, exames laboratoriais e dermatológico, teste do suor, microsco- \\
pia óptica e microscopia eletrônica de varredura dos fios de cabelo. \\
Resultados: Em duas irmãs afetadas encontramos no fundo de olho \\
dispersões pigmentares em pólo posterior da retina, com estafiloma da \\
mácula. Em dois irmãos foram encontradas as mesmas dispersões pigmen- \\
tares em pólo posterior, com maior pigmentação coloração amarelada em \\
área macular e sem estafiloma. A avaliação na microscopia óptica e \\
microscopia eletrônica de varredura dos indivíduos afetados confirmou a \\
SCAF.Emumamulhere emum homem nãoafetados todos os exames foram \\
normais, exceto que na MO e MEV encontramos algumas semelhanças com \\
os indivíduos afetados. Quanto ao modo de herança, o heredograma é \\
compatível com herança autossômica recessiva com expressão parcial no \\
heterozigoto. Conclusões: Há somente um relato na literatura internacio- \\
nal da associação de SCAF e coloboma ocular. Neste trabalho descreve- \\
mos os achados de nova distrofia macular associada à síndrome dos \\
cabelos anágenos frouxos, distrofia cujos achados fundoscópicos são \\
diferentes entre homens e mulheres. Por se tratar do primeiro relato na \\
literatura, os achados descritos sugerem fortemente que esta associação \\
pode ser parte de uma nova entidade nosológica.
\end{tabular}

Descritores: Alopecia; Cabelo/patologia; Síndrome dos cabelos anágenos frouxos; Distrofias hereditárias da córnea; Microscopia eletrônica de varredura; Hipotricose/ congênita

\section{INTRODUČ̃̃O}

Distrofias maculares são degenerações progressivas da retina e/ou coróide, afetando predominantemente a área macular e sem etiologia definida. Estas alterações tornam-se manifestas na infância como uma desordem determinada geneticamente, provavelmente na função das enzimas e metabolismo. Isto ocorre em forma de base displásica, em que células normais ou tecidos gradualmente se deterioram e morrem prematuramente ${ }^{(1)}$. As distrofias maculares são caracterizadas pelo seguinte elenco: 1) alterações predominantemente no pólo posterior; 2) de caráter familiar, bilateral e freqüentemente de envolvimento simétrico; 3) a distrofia vem associada com diminuição da acuidade visual; 4) tem início em idade precoce; 5) tem progressão 
lenta e 6) geralmente sem alterações físicas gerais ou anormalidades laboratoriais ${ }^{(2)}$.

Síndrome dos cabelos anágenos frouxos (SCAF) é uma desordem que se apresenta precocemente na infância e se caracteriza por alopécia difusa ou localizada resultante de cabelos fracamente ancorados na fase anágena. Estes cabelos são facilmente e de forma indolor retirados do couro cabelu$\mathrm{do}^{(3-5)}$. Em revisão da literatura latino-americana (LILACs), não foram encontradas citações sobre a síndrome dos cabelos anágenos frouxos (SCAF). É conhecido na literatura internacional com o nome de "loose anagen hair syndrome (LAHS) ${ }^{(6)}$ ". A herança é autossômica dominante e os achados essenciais são: os cabelos serem facilmente retirados do couro cabeludo quando puxados, estes se encontrarem na fase anágena e há a ausência da camada externa e interna da raiz $^{(7)}$. Os achados característicos na microscopia eletrônica de varredura (MEV) são a presença de formações canaliculares que ocorrem ao longo do folículo piloso ${ }^{(4,8)}$.

Neste trabalho descrevemos uma família, com sete indivíduos; destes, quatro (dois irmãos e duas irmãs) tinham o achado incomum de distrofia macular e a SCAF. Há somente um relato descrito da associação entre a SCAF e alterações oculares (coloboma ocular) ${ }^{(9)}$. Não se encontram relatos na literatura entre a distrofia macular e a SCAF. Em face dos achados incomuns, encontrados na descrição desta família, somos levados a considerar que estas informações evidenciam o fato de que podemos estar diante de nova entidade nosológica.

\section{MÉTODOS}

Todos os 7 indivíduos da família do heredograma da figura 1 foram submetidos ao exame oftalmológico completo: 1) acuidade visual (AV), motilidade ocular, pressão intra-ocular (Po), biomicroscopia do vítreo e fundo de olho sob dilatação; 2) ecografia; 3) angiografia e 4) teste de cores (Ishihara e Farnsworth D-15), o exame de Farnsworth foi realizado monocularmente, com a melhor correção para longe e para perto, se acima de 40 anos de idade, ambos os testes de cores foram realizados sob iluminação natural. Além disso, foram levantados os seguintes exames:

- Exame dermatológico completo.

- Exames laboratoriais (sangue completo, provas de função hepática, dosagens de metabólitos no sangue, parcial de urina e parasitológico de fezes).

- Radiografia dos dentes.

- Teste do suor ${ }^{(10)}$.

- Microscopia óptica (MO) e MEV dos fios de cabelos (metalização com ouro e observação no aparelho de MEV-Philips SEM 505).

\section{RESULTADOS}

Descrevemos uma família de cor negra encaminhada de Paranaguá-PR, para ser atendida no serviço de oftalmologia do hospital de clínicas. Examinada pelo corpo clínico do departamento de Oftalmologia, este levantou a suspeita inicial de retinite pigmentosa inversa (Março de 1999). A família foi novamente examinada por um dos autores (MTS) no início de 2000 e uma anamnese cuidadosa evidenciou que os indivíduos afetados (dois irmãos e duas irmãs) tinham alterações confinadas no pólo posterior da retina, principalmente na mácula e associada à história da deficiência do crescimento dos cabelos. A suspeita inicial foi de distrofia macular e hipotricose congênita, devido a alguns relatos que há na literatura ${ }^{(11-13)}$. As alterações incluem distrofia macular cuja característica fundoscópica é a diferença entre os irmãos: nas duas irmãs há distrofia macular associada ao estafiloma; e nos irmãos há a distrofia macular com aumento de pigmentação amarelada na mácula. A história clínica e posterior investigação do cabelo determinou o diagnóstico da distrofia, mostrando tratar-se da associação incomum com a SCAF. Segundo os informantes, o pai dos pacientes (Figura 1. II-20) não apresentava problemas de visão ou quedas de cabelo. Realizamos o exame oftalmológico nos filhos dos afetados (Figura 1. IV 1-4) e os resultados foram normais; aparentemente não há comprometimento do cabelo. As radiografias dos dentes, exame das unhas, teste do suor e partes do exame oftalmológico (Motilidade oculares, Po e biomicroscopia do vítreo) foram normais em todos os pacientes examinados. Os exames laboratoriais também foram normais, exceto o paciente III-24 (Figura 1) que apresentou hipotireoidismo. A seguir descreveremos os pacientes do heredograma da figura 1. A análise desta genealogia permite supor que se trate de fenótipo com herança autossômica recessiva e expressão parcial no heterozigoto.

Caso III-25 (Figura 2). A paciente nega baixa acuidade visual ou perda de cabelos, no exame oftalmológico apresentava acuidade visual sem correção de 20/20 em ambos os olhos (AO), fundo de olho normais, teste de cores (Farnsworth D-15), ecografia e angiografia normais. Cabelos longos em todo o couro cabeludo que não se desprendem facilmente e pilificação normal no corpo. Exame de MO e na MEV dos fios de cabelo sem alterações, sendo que a paciente é a única que tem o exame de MEV sem alterações; portanto serve de controle para este tipo de exame.

Caso II-19 (Figura 3). A mãe nega qualquer dificuldade visual ou problemas com os cabelos desde a infância. Apresentava AV de 20/20 em AO sem correção, no teste de Farnsworth D-15 detectou-se alterações com achados incaracterísticos no olho direto (OD) e defeito deutan em olho esquerdo (OE). Os cabelos são curtos e não se desprendem com leve tração, e a pilificação corporal é normal. Na MO apresenta alguns fios de cabelos com distrofia. Na MEV encontrou-se alterações canaliculares em alguns fios que lembram a SCAF.

Caso III-20 (Figura 4). Irmão mais velho normal, nega qualquer problema visual ou perda de cabelo na infância, refere crescimento normal de cabelos e da barba, sendo que desenvolveu a calvície com 28 anos de idade. Apresentou exame 


\section{I}

II
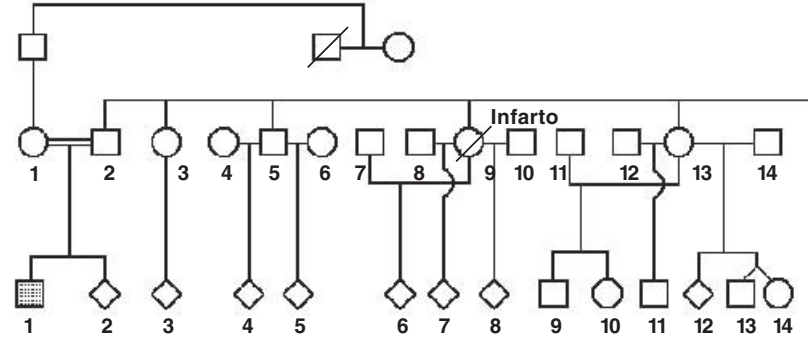

III

45

IV

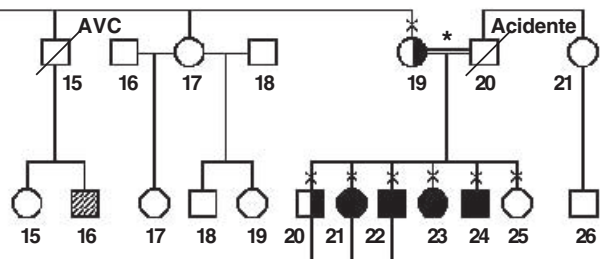

* Consangüinidade remota, grau ignorado.

Paralisia, vive em instituição.

Andou com 5 anos. Aos 18 anos ainda manifesta dificuldade de deambulação.

Sexo não referido.

Distrofia macular e síndrome dos cabelos anágenos frouxos.

Q(1) Expressãoparcial.

$x$ Examinados.

$\square$ Falecidos. Indicada a causa da morte (infarto=infarto do miocárdio, AVC = acidente vascular cerebral e acidente $=$ acidente de trabalho) .

Figura 1- Heredograma da família

oftalmológico e complementares normais. Os cabelos são curtos e não se desprendem com leve tração e a pilificação é normal. Na MO e MEV achados similares ao caso II-19.

Caso III-21 (Figura 5). A paciente refere diminuição da acuidade visual que teve início com 11 anos de idade. Refere piora progressiva da acuidade visual até a estabilização com 18 anos. Nega dificuldade de visão de cores ou dificuldade de visão à noite; queixa-se de fotofobia e lacrimejamento. Paciente tinha fios esparsos de cabelo até os 12 anos e após houve o crescimento, refere não necessitar de cortar os cabelos e que estes são facilmente arrancados, quando puxados. No exame

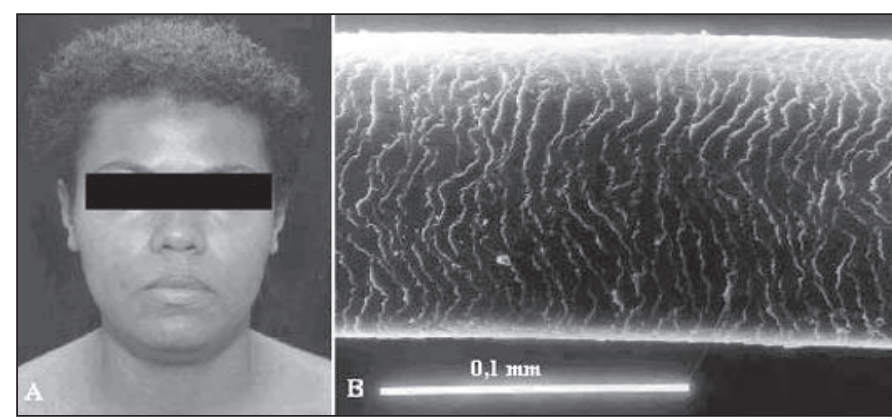

Figura 2 - Caso III-25, irmã com fundo de olho normal, 26 anos: A) Notase cabelos longos com disposição normal e B) MEV de fio de cabelo normal, mostrando superposição das células cuticulares da superfície e ausência de formação canalicular ao longo do fio. oftalmológico apresentava acuidade visual de conta dedos (CD) a 2 metros em AO, e refração sob cicloplegia de - 0,75 esf. $-1,00 \times 45$ em OD e $-0,75$ esf. em OE. Apresentou teste de cores na tabela de Ishihara anormais (lê somente a primeira e última prancha) e no teste de Farnsworth D-15 apresentou defeito tipo deutan em OD e OE. No fundo de olho apresentava lesões pigmentares com tamanhos e formas variadas; disco óptico e vasos retinianos são normais e com presença de estafiloma em área macular em AO. Na angiografia evidencia-se atrofia coriocapilar e atrofia do epitélio pigmentado da retina (EPR) em pólo posterior; disco óptico normal, vasos retinianos com perfusão normal, dispersão pigmentar e fibras de mielina em região

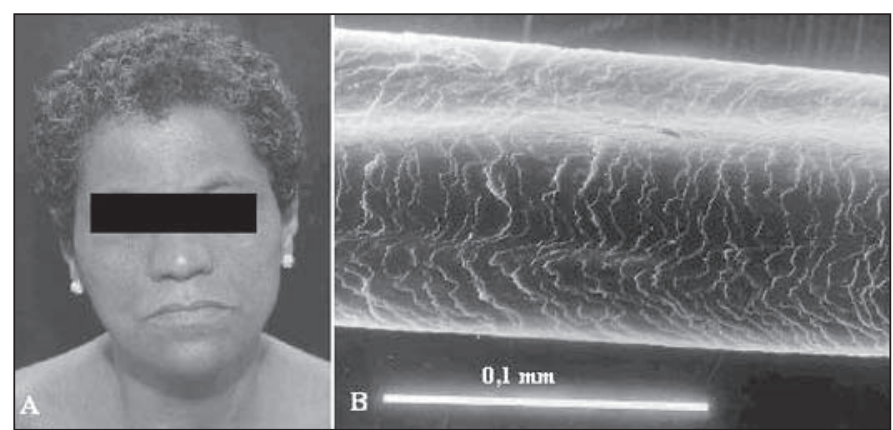

Figura 3 - Caso II-19, mãe com fundo de olho normal, 60 anos: A) Notase cabelos com disposição normal e B) MEV de fio de cabelo com formação canalicular característica da SCAF 


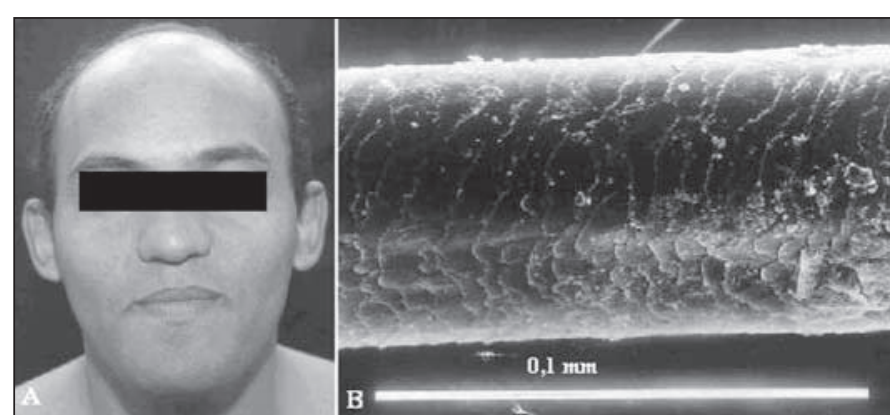

Figura 4 - Caso III-20, irmão com fundo de olho normal, 36 anos: A) Notase alopécia fronto-parietal e B) MEV de fio de cabelo com formação canalicular característica da SCAF

macular temporal inferior; na ecografia evidenciou-se estafiloma em área macular em AO e a espessura retinocoróidea foi normal. Apresentava cabelos curtos, mais na região frontoparietal e mais lisos que no restante do couro cabeludo. Pêlos terminais se desprendem com leve tração, principalmente nas regiões parietais e a pilificação corporal foi normal. Ao exame na MO evidencia-se fios de cabelos com ausência da lâmina externa e da raiz do cabelo, com distrofia e com a quase totalidade dos fios na fase anágena, na MEV evidenciam-se canalículos ao longo da extensão do folículo piloso; estes achados são compatíveis com a SCAF.

Caso III-22 (Figura 6). O paciente refere diminuição da acuidade visual, que teve início com 7 anos de idade. Refere piora progressiva da acuidade visual até os 14 anos. Nega dificuldade de visão para cores; refere dificuldade de visão à noite, lacrimejamento e fotofobia. Paciente tinha fios esparsos de cabelos até os 7 anos e após houve o crescimento. Refere que os cabelos crescem pouco, e que os cortes são infreqüentes; refere perda acentuada; e que os cabelos são facilmente arrancados, quando puxados. No exame oftalmológico apresentava acuidade visual de 20/200 em AO, e refração sob cicloplegia de $+1,00$ esf. $-1,50 \times 90$ OD e $-2,00 \times 90$ em OE. Apresentou teste de cores na tabela de Ishihara anormais (lê somente a primeira e última prancha) e no teste de Farnsworth D15 apresentou defeito tipo tritan em OD e deutan em OE. Na retinografia em $\mathrm{AO}$, apresenta dispersão pigmentar em pólo posterior da retina com formas e tamanhos variados e com aumento de pigmento amarelado em área macular, sem estafiloma em área macular, disco óptico e vasos da retina normais, na angiografia evidencia-se resultados similares ao caso III-21, exceto na ausência de estafiloma em área macular, na ecografia evidenciam-se ausência de estafiloma em área macular, espessura retinocoróidea normal e vítreo silencio em AO. Alopécia frontoparietal; pêlos se desprendem facilmente nesta região e pilificação diminuída nas axilas e tronco e pilificação genital. Exame na MO e MEV compatíveis com a SCAF, a exemplo do caso III-21.

Caso III-23 (Figura 7). A paciente refere diminuição da acuidade visual, que teve início aos 7 anos de idade. Refere
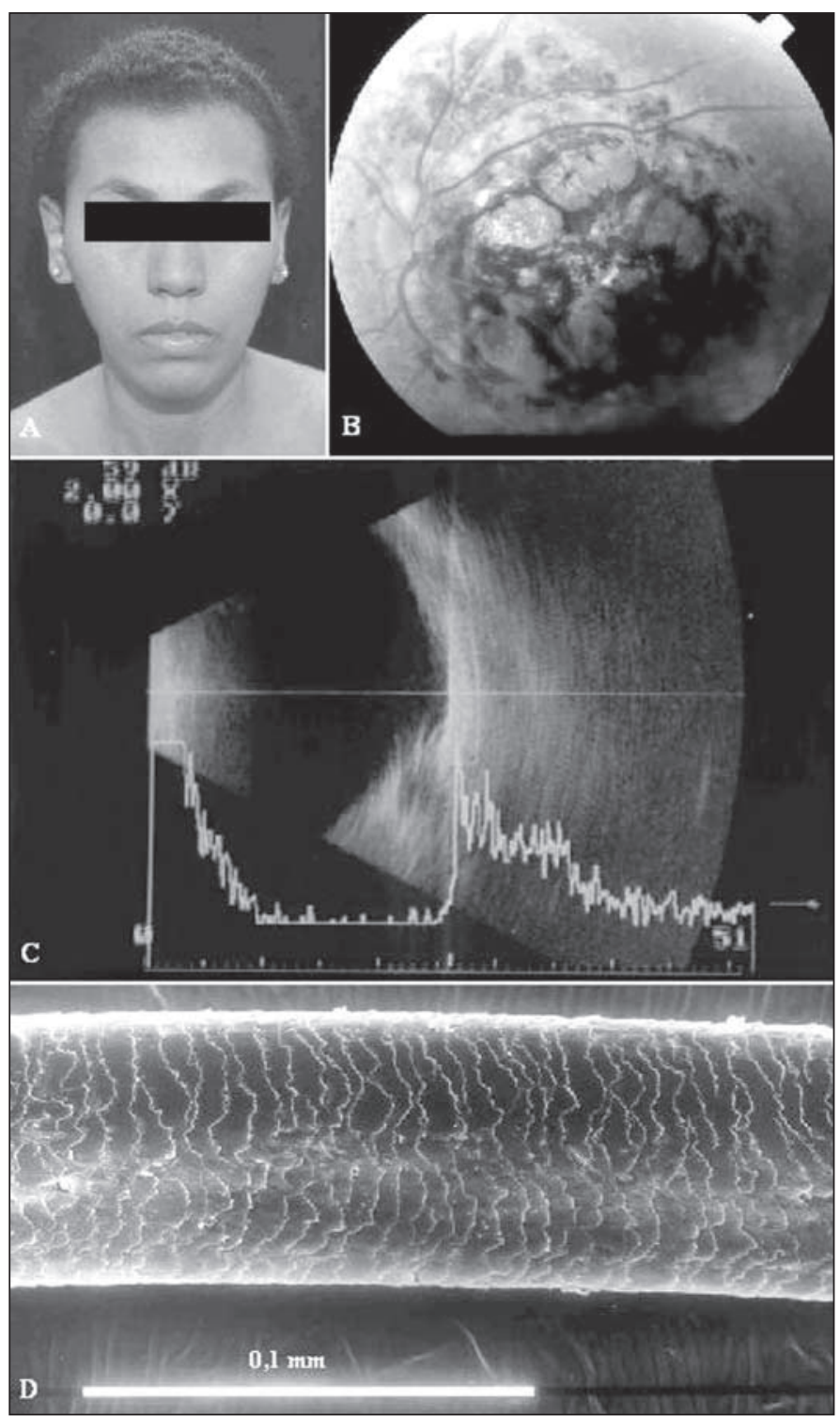

Figura 5 - Caso III-21, irmã afetada, 34 anos: A) Nota-se cabelos curtos mais intensos em região fronto-parietal; B) Dispersão pigmentar em pólo posterior da retina, vasos e papila normais e estafiloma em pólo posterior (área macular); C) Ecografia com espessura retinocoroideana normal e ausência de estafiloma e D) MEV de fio de cabelo com formação canalicular característica da SCAF

piora progressiva da acuidade visual até os 14 anos, quando o quadro se estabilizou. Nega dificuldade de visão para cores ou dificuldade de visão à noite. Refere fotofobia e lacrimejamento e que os cabelos crescem pouco. Paciente tinha fios esparsos de cabelos até os 12 anos e após houve o crescimento. Relata cortes infrequientes dos cabelos; e que os cabelos são facilmente arrancados, quando puxados. No exame oftalmológico apresenta acuidade visual de 20/200 em OD e CD a 2 metros em OE, ET em OE de 30 dioptrias e HT OD/OE de 20 dioptrias, e refração sob cicloplegia de - 0,75 esf. -1,00x60 em OD e - 1,00 esf. em OE. Apresentou teste de cores na tabela de Ishihara anormais (lê somente a primeira e última prancha) e no teste de 

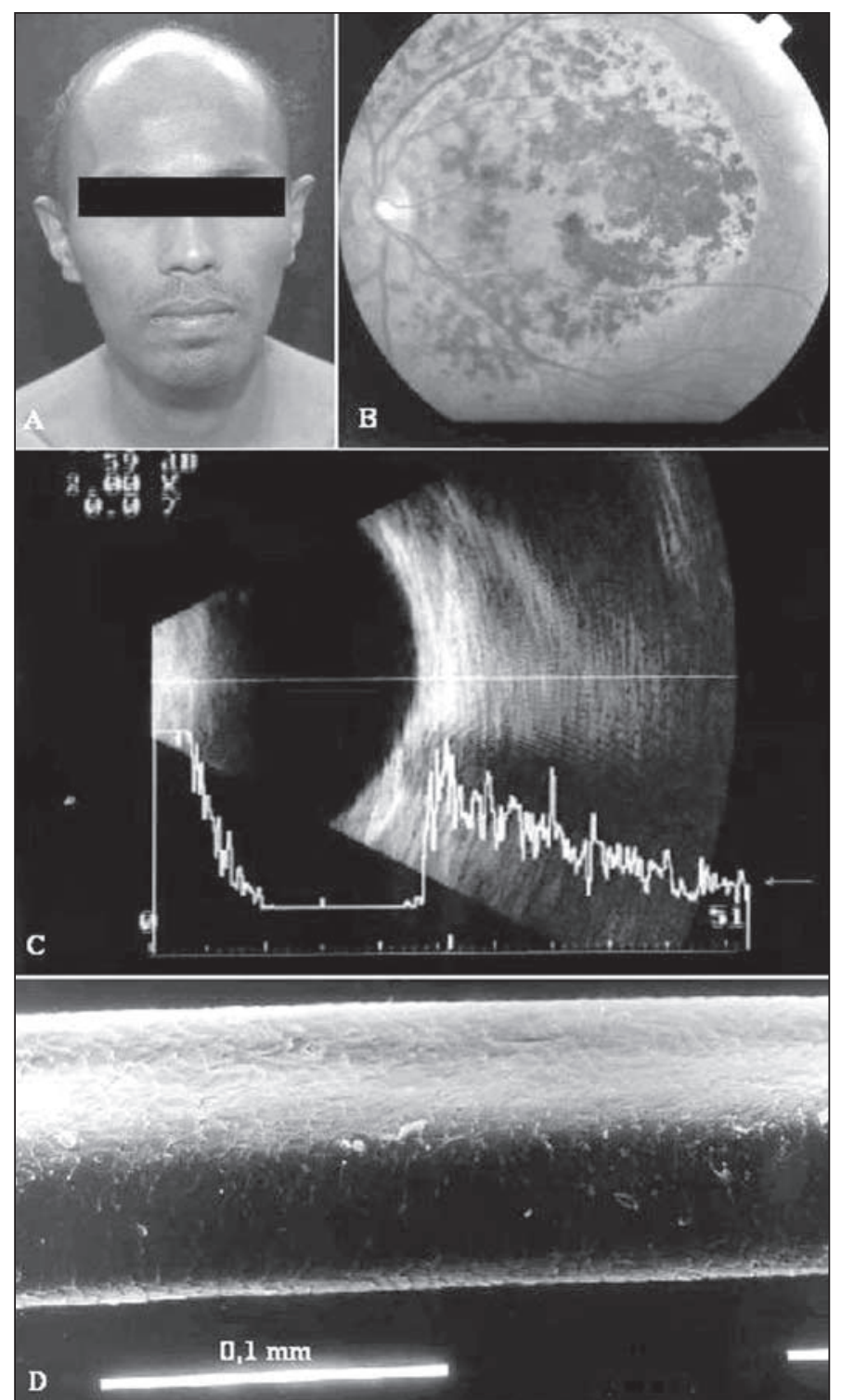

Figura 6 - Caso III-22, irmão afetado, 32 anos: A) Nota-se intensa alopécia em região fronto-parietal; B) Dispersão pigmentar em pólo posterior da retina, vasos e papila normais, com maior pigmentação amarelada em área macular e sem estafiloma; C) Ecografia com espessura retinocoroideana normal e ausência de estafiloma; D) MEV de fio de cabelo com alteração canalicular típica do SCAF

Farnsworth D-15 apresentou tritan em OD e deutan em OE. Apresentava fundo de olho, ecografia, angiografia, MO e MEV similares à irmã (Caso III-21).

Caso III-24 (Figura 8). O paciente refere diminuição da acuidade visual, que teve início com 7 anos de idade. Refere piora progressiva da acuidade visual até os 18 anos. Nega dificuldade de visão para cores. Refere dificuldade de visão à noite, lacrimejamento e fotofobia. Fez cirurgia de estrabismo aos 12 anos de idade; usa óculos desde os 4 anos. Paciente tinha fios esparsos de cabelos até os 7 anos e após houve o crescimento. Refere que os cabelos crescem pouco, os cortes são infreqüentes e que são facilmente arrancados, quando
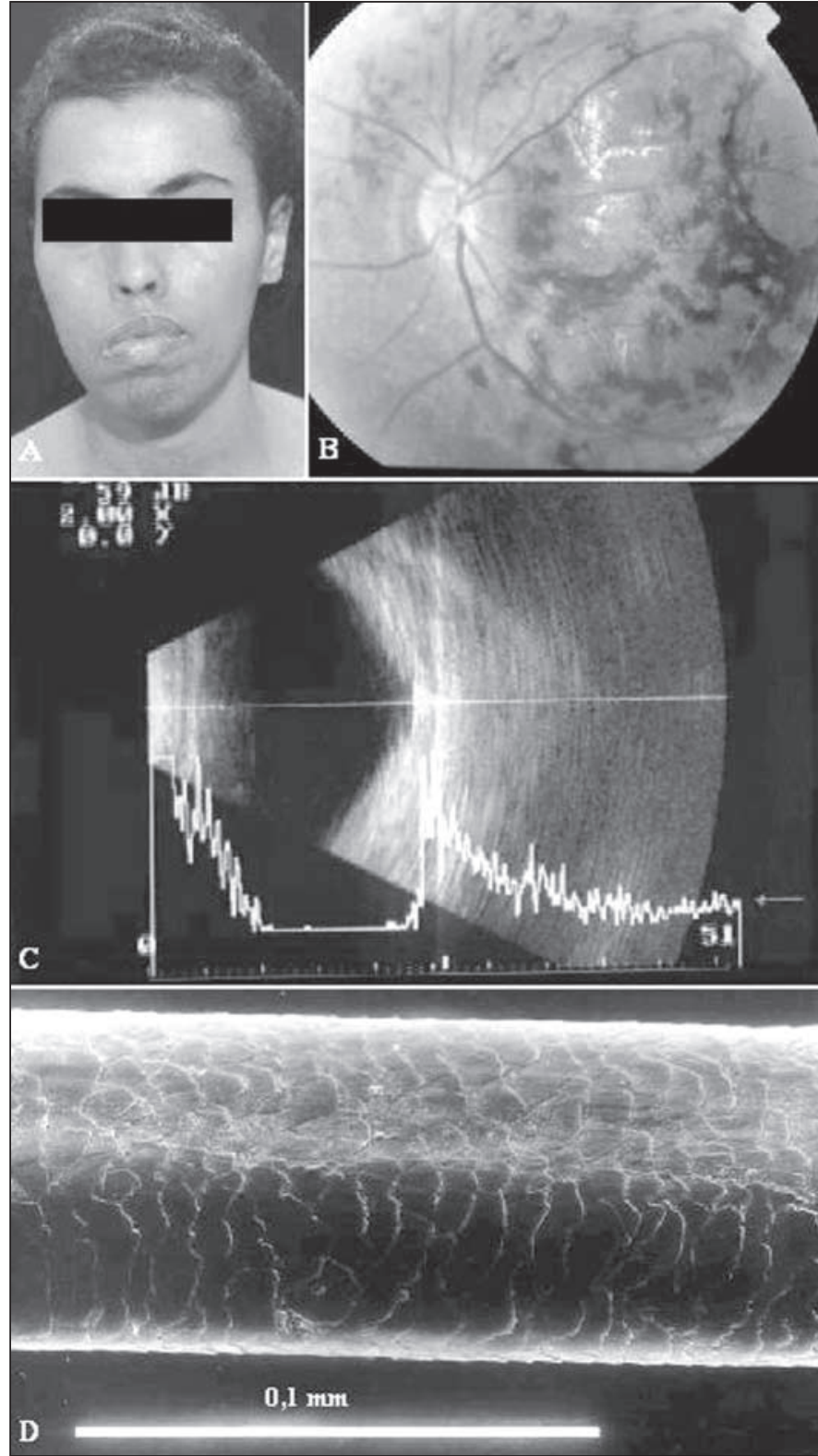

Figura 7 - Caso III-23, irmã afetada, 30 anos: A) Nota-se cabelos curtos mais intensos em região fronto-parietal; B) Dispersão pigmentar em pólo posterior da retina, vasos e papíla normais e estafiloma em área macular; C) Ecografia com espessura retinocoroideana normal e estafiloma em pólo posterior (área macular) e D) MEV de fio de cabelo com fromação canalicular típica da SCAF

puxados. No exame oftalmológico apresentava acuidade visual de 20/25 em OD e 20/200 em OE com correção, ET acomodativo e intermitente de 30 dioptrias. Prefere o OD com correção fica ortotrópico e ortofórico, refração sob cicloplegia de $+2,50$ esf. $-2,00 \times 15$ OD e $+2,50$ esf. 1,00x 180 em OE. Apresentou teste de cores na tabela de Ishihara anormais (lê somente a primeira e última prancha) e no teste de Farnsworth D-15 apresentou defeito tipo tritan em OD e OE. Vários erros com defeitos na faixa amarelo-azul, com a maioria dos erros ocorrendo nas pastilhas de $7-15$, com tendência do defeito tipo 

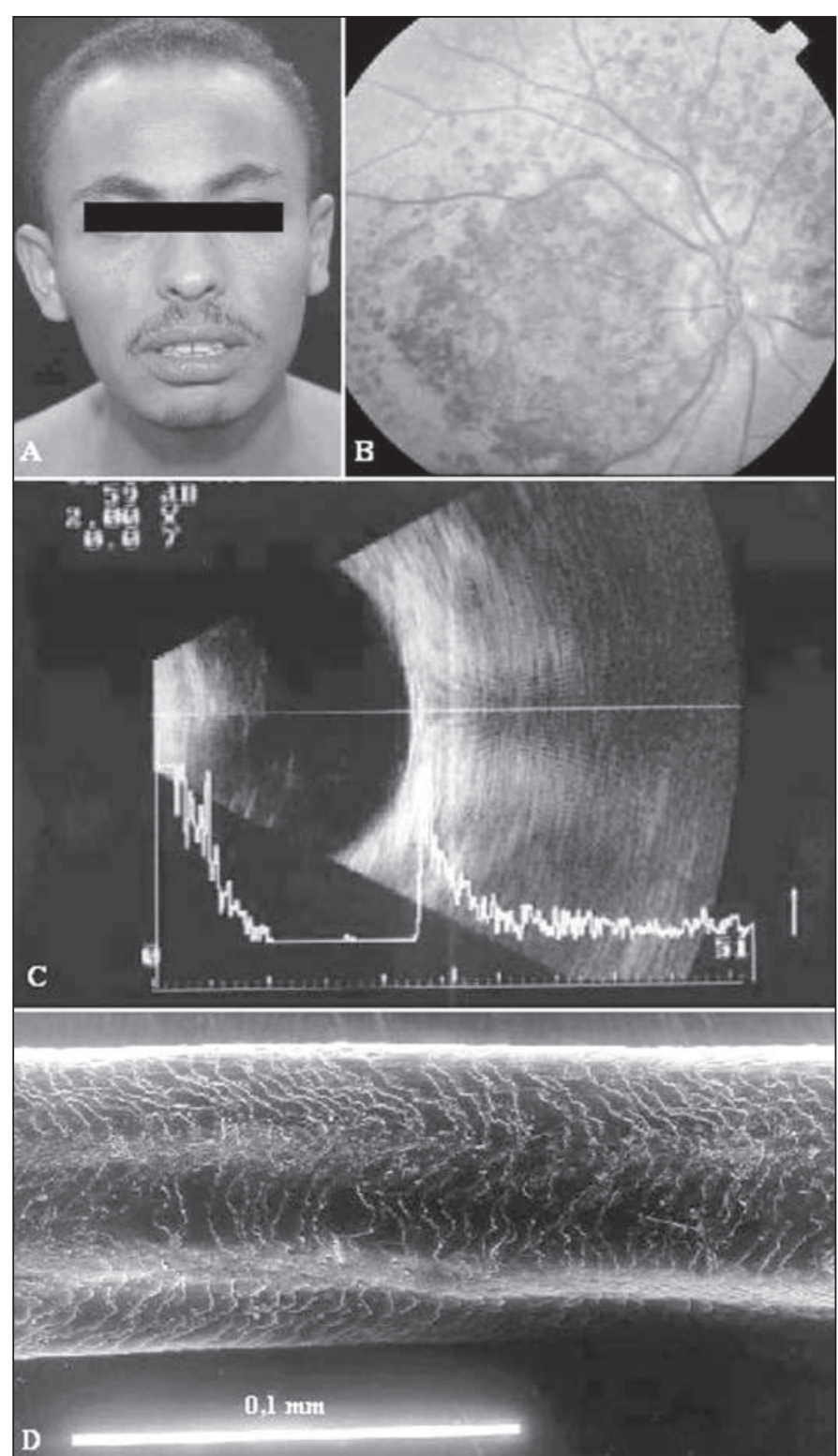

Figura 8 - Caso III-24, irmão afetado, 28 anos: A) Nota-se diminuição dos cabelos em região fronto-parietal; B) Dispersão pigmentar em pólo posterior da retina, vasos e papila normais com maior pigmentação amarelada em área macular e ausência de estafiloma; C) Ecografia com espessura retinocoroideana normal e ausência de estafiloma em pólo posterior e D) MEV de fio de cabelo com formação canalicular típica da SCAF

tritan. Apresentava fundo de olho, ecografia, angiografia, $\mathrm{MO}$ e MEV similares ao irmão (caso III-22).

\section{DISCUSSÃO}

A hipótese inicial dos pacientes afetados (Figura 1 - caso III-21, III-22, III-23 e III-24), foi a de retinite pigmentosa inversa, que é caracterizada por uma concentração anormal de pigmentos, envolvendo a mácula, podendo cursar com estreitamento dos vasos retinianos e palidez do disco óptico ${ }^{(14)}$. Os pacientes negam cegueira noturna e apresentavam disco óptico normal, vasos retinianos e dispersão pigmentar em todo o pólo posterior. Assim, descartamos a hipótese diagnóstica de retinite pigmentosa inversa. A perda de cabelo foi inicialmente encarada como hipotricose congênita, devido aos vários relatos da associação entre hipotricose congênita e distrofias maculares ${ }^{(11-13)}$. A característica da hipotricose congênita é que há o crescimento raro de cabelos, sendo os fios finos e curtos e não facilmente arrancáveis do couro cabeludo. Na MEV os fios apresentam pequena diminuição da densidade celular e alterações na arquitetura cuticular ${ }^{(15)}$. A hipotricose congênita está relacionada com várias doenças hereditárias e um dos sinais cardinais das displasias ectodérmicas. Displasias ectodérmicas formam amplo e complexo grupo nosológico, e se caracterizam por sinais de pêlo menos duas das seguintes estruturas: cabelo, dentes, unha e glândulas sudoríparas ${ }^{(16)}$. O envolvimento de cabelo e olho nas displasias ectodérmicas é um problema patogenético com defeito do desenvolvimento de nível embriológico, que afeta a ectoderme, já que estas duas estruturas tem a mesma origem embriológica ${ }^{(17)}$. Os pacientes afetados não apresentam quadro compatível com a hipotricose congênita, descartado pelo exame na MO e MEV. O exame das unhas, dentes e teste do suor normais afastam a possibilidade de displasia ectodérmica.

A distrofia macular nos indivíduos afetados tem como características clínicas a diminuição da visão na idade escolar (7-11 anos), com piora progressiva e estabilização da acuidade visual em torno de 14-18 anos. Negam os pacientes a dificuldade para visão de cores, queixam-se de fotofobia e lacrimejamento, sendo que as irmãs afetadas negam dificuldade de visão à noite, ao contrário dos homens, que se queixam de dificuldade de visão à noite. A fotofobia é queixa freqüente em pacientes que apresentam distrofia de cones. A dificuldade visual à noite é comum nos pacientes que apresentam retinite pigmentosa, com alteração no EPR, pelo fato de que os achados fundoscópicos são diferentes entre homens e mulheres, com a presença de estafiloma nas irmãs (evidenciadas pela ecografia e pela refração, pacientes apresentavam miopia) e aumento de pigmentação amarelada na mácula e sem estafiloma nos irmãos (evidenciadas pela ecografia e pela refração, pacientes apresentavam hipermetropia) e pela diferença nas queixas. Podemos supor que diferentes estruturas da retina possam estar afetando os irmãos. Para esclarecer este fato os autores irão submeter os pacientes ao exame eletrofisiológico (eletrorretinograma e eletro-oculograma) bem como ao campo visual computadorizado, para determinar o local das alterações funcionais na retina (resultados a serem discutidos em uma publicação posterior).

Os pacientes afetados com distrofia macular apresentaram alterações no teste para visão de cores. A mãe dos pacientes (caso II-19) apresentou achados incaracterísticos no OD, por causa da provável alteração no cristalino e as irmãs (caso III21 e III-23) apresentaram pior AV e a tendência do defeito no teste de Farnsworth D-15 foi do tipo deutan. Nos irmãos (caso 
III-22 e III-23) apresentaram melhor AV e a tendência do defeito foi do tipo tritan. Estes achados correlacionam-se bem com a $\mathrm{AV}$ em pacientes com retinosquisis ligados ao $\mathrm{X}$ em que os defeitos do tipo tritan, quando estão no início da patologia, apresentam melhor AV; com a progressão da patologia, os pacientes apresentam o defeito tipo deutan, com a piora da $\mathrm{AV}^{(18)}$.

Os pacientes afetados tiveram o diagnóstico de SCAF, pelos seguintes critérios: 1) Perda fácil dos cabelos e estes são facilmente arrancados quando puxados, sem dor; 2) história de não crescimento dos cabelos e poucos cortes deles; 3 ) a maioria dos cabelos estão em fase anágena, com ausência da camada interna e externa da raiz do cabelo e distrofia na $\mathrm{MO}$ e presença de formações canaliculares na MEV e 4) todos os exames realizados descartaram a possibilidade da displasia ectodérmica.

Há somente um relato na literatura da associação da SCAF e alterações oculares (coloboma ocular) em dois irmãos, sendo que na irmã o achado foi de coloboma da íris e da coróide em OD e o OE foi normal. No irmão havia coloboma de coróide envolvendo o disco óptico em $\mathrm{AO}^{(9)}$. Cumpre considerar que neste relato os cabelos não eram facilmente arrancáveis do couro cabeludo. $\mathrm{O}$ autor conclui que era a SCAF, pelas evidências clínicas e histológicas que lembravam a SCAF; portanto este diagnóstico é questionável por não preencher todos os critérios para o diagnóstico da SCAF.

$\mathrm{O}$ presente relato diferencia-se da literatura, porque os pacientes afetados apresentavam cabelos negros e não loiros ou castanhos, como descrevem a maioria dos autores ${ }^{(3,6)} \mathrm{e}$ também devido à existência de características da SCAF em pacientes não afetados (caso II-19 e III-20).

A observação de alterações estruturais do cabelo na MEV e com alguns fios distróficos na MO, na mãe (Figura 3 - caso II-19) e em um dos irmãos afetado (Figura 4 - caso III-20), em uma intensidade menor que as evidenciadas nos indivíduos com distrofia de mácula, poderia ser interpretada como evidência de manifestação no heterozigoto. Temos como exemplo a provável expressão parcial em heterozigotos quanto ao gene que determina a síndrome de Tel Hashomer ${ }^{(19)}$, de herança autossômica recessiva. Do ponto de vista da etiologia genética, outro aspecto deve ser considerado: como a mãe dos afetados apresenta a expressão fenotípica, poderíamos supor que estas alterações sejam determinadas por gene autossômico dominante com expressividade variável, o que é compatível com a transmissão vertical observada.

A observação de diferenças na expressão da distrofia, entre os irmãos e irmãs afetados, poderia ser explicada pela ação de genes modificadores que influenciariam a manifestação fenotípica. Esta hipótese encontra respaldo em observações recentes relacionadas a várias síndromes de etiologia genética em humanos, bem como estudo em modelos animais ${ }^{(20)}$. Esses estudos trazem a perspectiva de elucidação dos mecanismos que levam à variabilidade fenotípica. Como exemplo temos a identificação mediante a análise de ligação em uma família com afetados pela síndrome de Van der Woude (autossômica dominante com expressividade variável e penetrância incompleta), em que a existência de um gene no braço curto do cromossoma 17 junto com o gene da síndrome (cromossoma 1, braço curto) aumenta a probabilidade de que o indivíduo tenha fissura de palato $^{(21)}$.

A definição do modo de herança, o delineamento fenotípico e a determinação dos genótipos dos indivíduos analisados só acontecerá, quando outras famílias forem estudadas e o gene que determina a distrofia for identificado e clonado, permitindo estudos pela análise direta do DNA. Amostras de sangue periférico com a extração do DNA foram coletadas dos pacientes examinados, visando a estudos posteriores, que poderão contribuir para o conhecimento da localização do gene.

\section{CONCLUSÃO}

Concluindo, descrevemos um achado único da associação de distrofia macular com a SCAF. Devido aos achados inéditos, sugerimos que esta associação possa fazer parte de uma nova entidade nosológica.

\section{AGRADECIMENTOS}

A Profa. Daura Regina Eiras Stofella pela realização da microscopia eletrônica de varredura dos fios de cabelos, ao Prof. Fillus Neto pela realização da microscopia óptica nos fios de cabelos e a Profa. Lucia Ventura Urbano da Disciplina de Oftalmologia da Universidade Federal de Minas Gerais (UFMG), na interpretação do teste de cores.

\section{ABSTRACT}

Purpose: To describe the ophthalmological, dermatological, light microscopy (LM) and scanning electron microscopy (SEM) findings of a new macular dystrophy associated with the loose anagen hair syndrome (LAHS). Methods: A family of seven patients, four of them affected, was examined. The patients underwent a complete ophthalmological examination, color test (Ishihara and Farnsworth D-15), ecography, angiography, laboratory and dermatological tests, sweat test, light microscopy and scanning electron microscopy of the hair. Results: In two affected sisters we found on eye fundoscopy pigmentary dispersions in the posterior pole of the retina, with macular staphyloma. In two brothers, the same pigmentary dispersions in the posterior pole was found, with more pigmentation and a yellow coloring in the macular area and without staphyloma. The light microscopy and scanning electron microscopy evaluation of the affected individuals confirmed loose anagen hair syndrome. In a not affected woman and man all examinations were normal, except the light microscopy and scanning electron microscopy that showed some similari- 
ties with the affected individuals. As for the way of inheritance, the pedigree is compatible with autosomal recessive inheritance with partial expression of the heterozygote. Conclusions: There is only one report in the international literature of loose anagen hair syndrome association with ocular coloboma. In this study we describe the findings of a new macular dystrophy associated with the loose anagen hair syndrome, a dystrophy whose fundoscopy findings are different between men and women. Since it is the first report in the literature, the described findings strongly suggest that this association can be part of a new nosological entity.

Keywords: Alopecia; Hair/pathology; Loose anagen hair syndrome; Hereditary corneal dystrophies; Electron scanning microscopy; Hypotrichosis/congenital

\section{REFERÊNCIAS}

1. Waardenburg PJ. Genetics in ophthalmology. Springfield, IL: Thomas; 1963; vol. 2.

2. Deuteman AF. The hereditary dystrophies of the posterior pole of the eye. Springfield, IL: Thomas; 1971.

3. Dawber R, Van Neste D. Perda de cabelos. In: Dawber R, Van Neste D. editores. Doenças do couro cabeludo e cabelo. São Paulo: Editora Manole; 1996;3:81-2.

4. Azón-Masoliver A, Ferrando J. Loose anagen hair in hypohidrotic ectodermal dysplasia. Pediatric Dermatol 1996;13:29-32.

5. O'Donnell BP, Sperling LC, James WD. Loose anagen hair syndrome. Int J Dermatol 1992;31:107-9.

6. Hamm H, Traupe H. Loose anagen hair of childhood: the phenomen of easily pluckable hair. J Am Acad Dermatol 1989;20:242-8.
7. Baden HP, Kvedar JC, Magro CM. Loose anagen hair as a cause of hereditary hair loss in children. Arch Dermatol 1992;28:1349-53.

8. Lalevic-Vasic B, Polic D, Milinkovic R. Loose anagen hair syndrome. Ann Dermatol Venereol 1990;117:701-7.

9. Murphy MF, McGinnity FG, Allen GE. New familial association between coloboma and loose anagen syndrome. Clin Genet 1995;47:214-6.

10. LeGrys VA. Sweat testing for the diagnosis of cystic fibrosis: practical considerations. J Pediatr 1996;129:892-7.

11. Kroll P. Congenital dystrophy of the pigment layer of the posterior pole with congenital total hypotrichosis. Klin Monatsbl Augenheilkd 1981;178:118-20.

12. Becker M, Rohrschneider K, Tilgen W, Weber BH, Volcker HE. Familial juvenile macular dystrophy with congenital hypotrichosis capitis. Ophthalmologe 1998;95:233-40.

13. Souied E, Amalric P, Chauvet ML, Chevallier C, Le Hoang P, Munnich A. et al. Unusual association of juvenile macular dystrophy with congenital hypotrichosis occurrence in two siblings suggesting autosomal recessive inheritance. Ophthalmic Genet 1995;16:11-5.

14. Duke-Elder S, Dobree JHS. Degenerations and dystrophyes. In: Duke-Elder S. editor. System of Ophthalmology. Diseases of the retina. St. Louis: Mosby; 1967;5(10):591-3.

15. Cambiaghi S, Barbareschi M. A sporadic case of congenital hypotrichosis simplex of the scalp: difficulties in diagnosis and classification. Pediatr Dermatol 1999;16:301-4.

16. Freire-Maia N, Pinheiro M. Ectodermal dysplasias-a clinical and genetic study. New York: Alan R Liss; 1984.

17. Freire-Maia N. Ectodermal dysplasias revisited. Acta Genet Med Gemellol 1977;26:121-31.

18. Harris GS, Yeung J. Maculophathy of sex-linked juvenile retinoschisis. Can J Ophthalmol 1976;11:1-10.

19. Pagnan NAB, Gollop TR, Lederman H. The Tel-Hashomer camptodactyly syndrome: report of a new case and review of the literature. Am J Med Genet 1988;29:411-7.

20. Asher JII Jr, Harrison RW, Morell R, Carey ML, Friedman TB. Effects of Pax3 modifier genes on craniofacial morphology, pigmentation, and viability: a murine model of Waardenburg syndrome varion. Genomics 1996;34:285-98.

21. Sertie AL, Souza AV, Steman S, Pavanello RC, Passos-Bueno MR. Linkage analysis in a large Brazilian family with Van der Woude syndrome suggests the existence of a susceptibility locus for cleft palate at 11p11.2-11.1. Am J Hum Genet 1999;65:433-40.

\section{CONGRESSO INTERNACIONAL DA SOCIEDADE} BRASILEIRA DE OFTALMOLOGIA - SBO

\section{A 29 DE JUNHO DE 2002}

\section{HOTEL GLÓRIA - RJ}

\section{INFORMAÇÕES:}

Tels.: (21) 2557-7298 • Fax: (21) 2205-2240

e-mail: sbo@sboportal.org.br 